\title{
Osteoma of Internal Auditory Canal - A Rare Pathology
}

\author{
Bhushita Nilesh Guru¹, Bhushan Narayan Lakhkar²
}

${ }^{1}$ Department of Radiology, Datta Meghe Institute of Medical Sciences, Sawangi (Meghe), Wardha, Maharashtra, India. ${ }^{2}$ Department of Radiology, Datta Meghe Institute of Medical Sciences, Sawangi (Meghe), Wardha, Maharashtra, India.

\section{PRESENTATION OF CASE}

A 27-year-old female patient visited the Department of Radiology with complaints of right sided facial palsy and sensory-neural hearing loss from past 10 years. Otologic examination revealed both tympanic membranes to be normal. Audiometry revealed right sided sensory neural hearing loss. The patient was also having multiple facial spasms.

HRCT temporal bone of the patient was done, and it showed a well-defined round to oval bony out-pouching arising from posterior wall of right internal auditory canal causing severe stenosis of porus acusticus with only $7 \mathrm{~mm}$ patency. (Figure 1) The lesion was noted to be over the vestibulo-cochlear and the facial nerves. The cortex of the lesion was continuous with that of the parent bone. (Figure 2). The left internal auditory canal was normal.

\section{DISCUSSION}

Osteomas are one of the common benign bone pathologies. They are often confused with exostosis; hence, the diagnosis of osteoma and exostosis go hand in hand. The most common sites for osteomas include the frontal sinus, ethmoid sinus, the bony calvarias and external auditory canal. ${ }^{1}$

Osteomas are benign slow growing tumours of the bone. It is one of the commonest pathologies within the external auditory canal, however they are one of the rarest pathologies of the internal auditory canal. In the external ear they occur as a result of repeated trauma, infection or irritating stimuli; but its pathogenesis within the internal auditory canal is still unknown. Till now only 21 cases of the same have been reported in literature.

The most common differential diagnosis of osteomas is exostosis; however, exostosis generally appears bilaterally. ${ }^{3}$ Biopsy of the lesions of internal auditory canal is not possible; hence, the radiographic appearance plays an important role in differentiating exostosis from osteoma or any other bony lesion. Exostoses are usually multiple and bilateral, having a smooth border, have a broad based and grow towards internal auditory canal; whereas, osteomas are solitary, stalked lesion with its marrow continuous with that of the parent bone. ${ }^{4}$

There are a number of causes that can compromise the lumen of internal auditory canal, like Paget's disease, otosclerosis or fibrous dysplasia. They may both lead to expansion of the bones of canal or new bone formation within the canal and cause its narrowing. However, typical appearance of an osteoma helps to differentiate it from rest of the causes. ${ }^{5}$

Such patients usually present with sensory neural hearing loss, tinnitus, or facial palsy and spasm. It might be due to either direct compression or the lesion acting like a fulcrum causing repeated indentations over the nerves with movement. ${ }^{5}$ An osteoma will narrow the caliber of the canal and compress the $7^{\text {th }}$ and $8^{\text {th }}$ cranial nerve.

Treatment is still controversial and is determined by the severity of the symptoms. Asymptomatic patients are usually observed every 6 months. Patients with mild symptoms are advised serial audiograms and CT scans. Patients with severe symptoms, such as those with progressive hearing loss or vertigo and near complete occlusion of the IAC may require surgical excision and nerve decompression before irreversible damage occurs. ${ }^{2}$
Corresponding Author:

Dr. Bhushita Nilesh Guru, Associate Professor,

Datta Meghe Institute of

Medical Sciences, Sawangi (M),

Wardha, Maharashtra, India.

E-mail: bhushitalakhkar@gmail.com

DOI: $10.14260 /$ jemds/2020/625

How to Cite This Article:

Guru BN, Lakhkar BN. Osteoma of internal auditory canal: a rare pathology. J Evolution Med Dent Sci 2020;9(38):28632864, DOI: $10.14260 /$ jemds/2020/625

Submission 19-06-2020,

Peer Review 13-08-2020

Acceptance 19-08-2020,

Published 21-09-2020.

Copyright (C) 2020 Bhushita Nilesh Guru et al. This is an open access article distributed under Creative Commons Attribution License [Attribution 4.0 International (CC BY 4.0)] 


\section{Jemds.com}

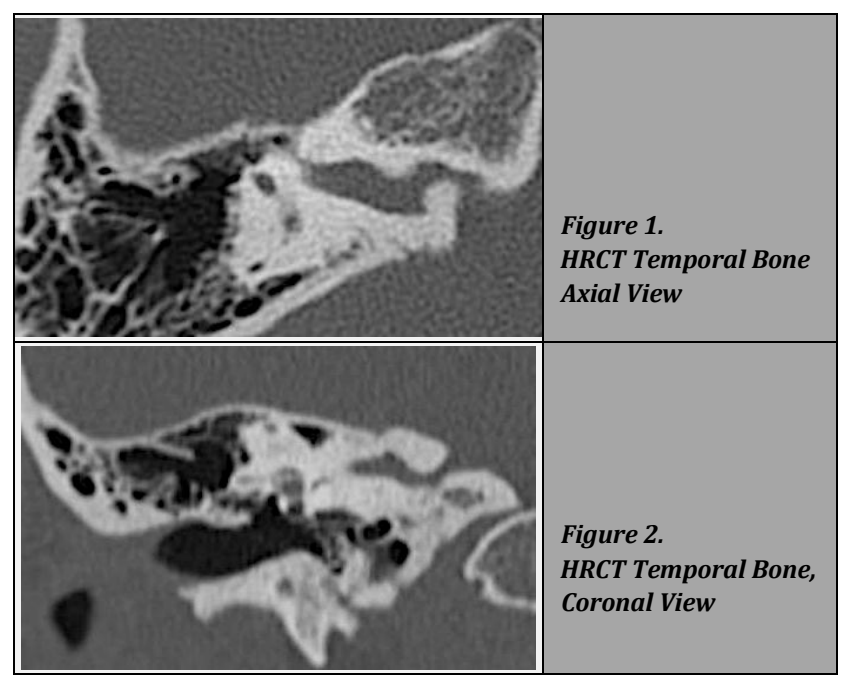

Well defined bony projection noted arising from the internal auditory canal causing its narrowing.

\section{CONCLUSIONS}

Bony osteoma is one of the rarest pathologies of internal auditory canal. Patients presenting with unilateral hearing loss or palsy should be investigated for it and should be treated according the severity of symptoms.

Financial or Other Competing Interests: None.

\section{REFERENCES}

[1] Liétin B, Bascoul A, Gabrillargues J, et al. Osteoma of the internal auditory canal. Eur Ann Otorhinolaryngol Head Neck Dis 2010;127(1):16-9.

[2] Baik FM, Nguyen L, Doherty JK, et al. Comparative case series of exostoses and osteomas of the internal auditory canal. Ann Otol Rhinol Laryngol 2011;120(4):255-60.

[3] Ciorba A, Aimoni C, Bianchini C, et al. Bilateral osseous stenosis of the internal auditory canal: case report. Acta Otorhinolaryngol Ital 2011;31(3):177-80.

[4] Nguyen L, Baik FM, Doherty JK, et al. Exostoses and osteomas of the internal auditory canal. Laryngoscope 2010;120 Suppl 4:S215.

[5] Vrabec JT, Lambert PR, Chaljub G. Osteoma of the internal auditory canal. Archives of Otolaryngology -Head \& Neck Surgery 2000;126(7):895-8. 